\title{
Lambda potential in the rhesus monkey
}

\author{
JÓZSEF SZIRTES, MAGDA MARTON, and PÉTER BREUER \\ Institute for Psychology, Budapest, Hungary
}

\begin{abstract}
Averaged lambda potentials associated with saccadic eye movements were studied in five rhesus monkeys. The influence of field luminance and of saccade size on the latency/amplitude of potentials recorded transcortically from within primary visual cortex were analyzed. Decrease in the luminance of the stimulus field led to a decrease in the amplitude of the first prominent negative component $\left(\mathrm{N}_{1}\right)$ and to a lengthening of the late positive component $\left(\mathrm{P}_{3}\right)$. Saccade size had a different influence on the $N_{1}$ and $P_{3}$ components. $N_{1}$ latency from saccade onset changed only slightly with increase in saccade size. $P_{3}$ latency, on the other hand, increased significantly when measured from saccade onset, but showed no latency differences with saccade sizes when measured from saccade offset. These results support the conclusion drawn from human studies as well that the $\mathrm{N}_{1}$ component is related to events at the onset of and during saccades (e.g., suppression), whereas $\mathrm{P}_{3}$ is linked to saccade offset and reflects information pickup in a new fixation.
\end{abstract}

Brain potentials associated with visual scanning (lambda waves) have been extensively investigated in humans (Barlow \& Ciganek, 1969; Becker, Hoehne, Iwase, \& Kornhuber, 1972; Kurtzberg \& Vaughan, 1973; Scott \& Bickford, 1969; Yagi, 1979), but relatively few studies deal with lambda potentials in animals (Cohen \& Feldman, 1971; Rhodes, Lanoir, Saier, \& Naquet, 1962; Scott, Lichtenfeld, \& Bickford, 1968). Scott et al. (1968) noted that the lambda potentials that appear in monkey and man are similar. They also pointed out that no response over the visual cortex accompanies eye movements performed in darkness in either species. However, questions concerning the functional significance of the different components of the lambda complex has received little attention in animal studies.

In humans, significant observations have been made about the relations among stimulus qualities, saccade characteristics, and the lambda potential. For example, Kurtzberg and Vaughan (1977) and Yagi (1979) showed that the averaged lambda potential ("lambda complex") is made up of a sequence of components, some of which are associated with the onset of the saccade, while others are associated with its offset. These two types of components (called "saccadic" and "fixational" by Kurtzberg \& Vaughan) can be distinguished by investigating saccades of different sizes. Although the functional significance of the two classes of components has been interpreted within an extensive theoretical framework (Kurtzberg

The authors would like to thank Diane Kurtzberg, Herbert G. Vaughan, Jr., and Gyorgy Gergely for their advice and help during preparation of the manuscript. A portion of these data was presented at a poster session of the XXVIIIth International Congress of Physiology in Budapest, July 1980 . The authors' mailing address is: Institute for Psychology, Pf. 398, H-1394 Budapest 62, Hungary.
\& Vaughan, 1977; Yagi, 1979), there nevertheless still remains some disagreement concerning the origin and functions of certain of the components. Recording the lambda complex in primate visual cortex may help to resolve some of these issues.

The aim of the present study was to describe the influence of stimulus field and saccade size on the waveform of the averaged lambda complex recorded over the visual cortex in rhesus monkeys. As in the human studies, we examined the latency characteristics of the different components in relation to the onset and offset of saccades of different sizes, paying special attention to the most prominent negative and positive components $\left(\mathrm{N}_{1}\right.$ and $\mathrm{P}_{3}$, in Yagi's nomenclature). The behavior of the components was also assessed during saccades performed across visual fields (gratings) of different luminance/contrast values.

\section{METHOD}

The experiments were performed on five juvenile rhesus monkeys (Macaca mulatta). Under Nembutal anesthesia, platinum black electrode pairs were implanted in the primary visual cortex. The epidural part of the transcortical platinum pair was a 2-mmdiam coil that rested on the dura, and the subcortical reference probe, with a $1.5-\mathrm{mm}$ platinized tip, extended through the center of the coil 5-6 mm into the cortex. The electrodes and the receptacles for immobilizing bars were secured to the skull with dental acrylic. The animals were allowed to recover for 14-21 days before recording was started.

During the experimental session, the monkey, with its head restrained, sat in a primate chair facing a tangent screen $70 \mathrm{~cm}$ in front of it. Eye movements were recorded by electrooculography (EOG) using dc amplifiers. Beckman nonpolarization skin electrodes were affixed with collodion at the outer canthus of cach eye and above and below one eye. Brain activity was recorded with a Beckman Accutrace EEG machine and stored, along with EOG, on a magnetic tape (Analog-14, Philips). Surface electrodes were always connected to Grid 1 , in which a negative change relative to the deep electrode leads to a negative potential in the record. Overall band-pass of the system was .16-1,250 Hz. Aver- 
aging was performed off-line either on a summing averager (Neurolog) or on a special-purpose computer (TPAi, KFKI). Eye movements were sorted according to the amplitude of horizontal saccades. Three categories of saccade size were used: saccades with an amplitude of 8-12 deg (mean $10 \mathrm{deg}$ ), 16-24 deg (mean $20 \mathrm{deg}$ ), and 26-33 deg (mean $30 \mathrm{deg}$ ). Eye movements were calibrated by measuring the amplitude of saccades made to a sequence of unexpected on and off LED fixation lamp flashes. Except when eliciting saccades for calibration purposes, the eye movements of the animals were spontaneous. The behavior of the animals was always monitored by one of the experimenters outside the viewing range of the animal.

There were three viewing conditions. Conditions 1 and 2 served to assess the effects of saccade size and field luminance on lambda potentials. In the first condition, 2-deg-wide black and white vertical stripes with an overall luminance of $15 \mathrm{~cd} / \mathrm{m}^{2}$, as measured by a Tektronix J16 photometer, were used. The same grating pattern was employed in Condition 2, its luminance attenuated by $1.5 \mathrm{log}$ units, using a Kodak Wratten neutral density filter. Finally, in Condition 3, saccades were performed in total darkness. Four animals participated twice, and one animal once, in the experiment.

For two of the animals, the recording sites were determined histologically. In the remaining three, histological verification is not available since additional experiments are presently being conducted with these monkeys. However, the stereotaxic coordinates were the same as those in the two verified cases.

\section{RESULTS}

\section{The Effect of Stimulus Luminance}

Table 1 presents the mean latency values measured from saccade onset of the $N_{1}$ and $P_{3}$ components of lambda potentials accompanying saccades of different sizes. As shown there, decreasing the luminance value of the stimulus field (Condition 2) led to a shift in latency of both the prominent negative and positive components. Comparison of the $\mathrm{N}_{1}$ latencies across all saccade sizes revealed a significant difference between Conditions 1 and $2, N_{1}$ peaking slightly earlier when the gratings were viewed under high luminance. (Overall peak latencies were 60.7 vs. $72.2 \mathrm{msec}, \mathrm{p}<.05$, Wilcoxon matched-pairs signedranks test.) Figure 1 illustrates the grand average waveforms of the five animals.

The influence of luminance was also evaluated within the three size categories. Although neither comparison reached significance in the Wilcoxon test, the

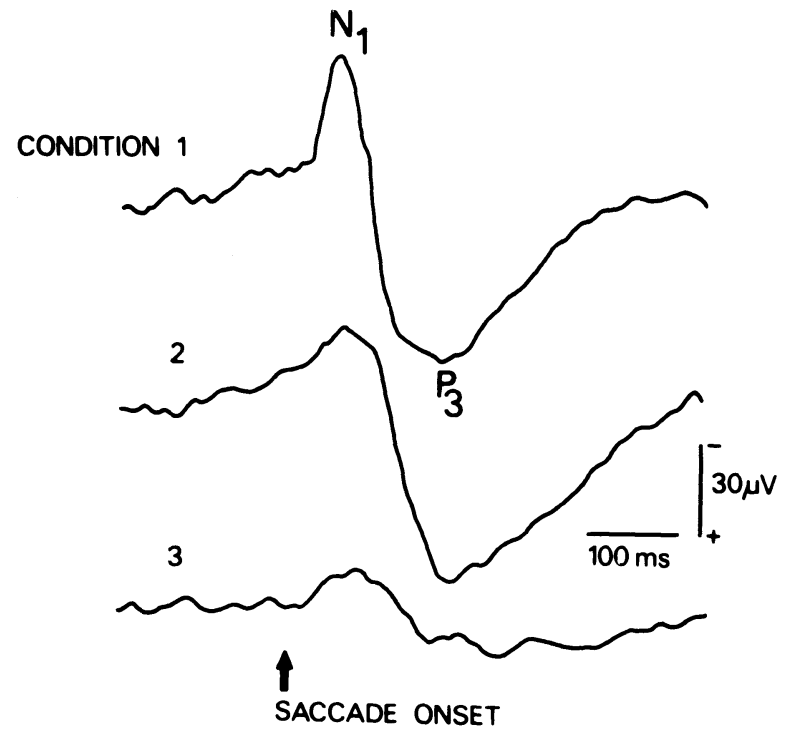

Figure 1. Grand mean lambda potentials for the five animals averaged across all saccade sizes in each condition. Condition 1: grating with high luminance. Condition 2: grating with low luminance. Condition 3: total darkness.

same tendency appeared in each category: the $N_{1}$ component peaked later in the low-luminance condition. This can be seen in Figure 2, which shows grand average waveforms, computed over the five animals, corresponding to the different saccade categories.

The amplitude of the $\mathrm{N}_{1}$ component across all saccade sizes was significantly different between Conditions 1 and 2; in the high-luminance condition, it was significantly greater than it was in Condition 2 . (Overall means 50.6 vs. $32.5 \mu \mathrm{V}, \mathrm{p}<.01$, Wilcoxon test.) This amplitude difference between the two conditions clearly appears both in the overall grand averages (Figure 1), and in the grand averages corresponding to saccade sizes (Figure 2).

The amplitude of the $\mathrm{N}_{1}$ component was also compared between Conditions 1 and 2 in the three size categories (Table 2). Although the difference in amplitude reached significance only in the case of sac-

Table 1

Means and Standard Deviations for $N_{1}$ and $P_{3}$ Latencies (in Milliseconds) From Saccade Onset in Conditions 1 and 2

\begin{tabular}{|c|c|c|c|c|c|c|}
\hline \multirow[b]{3}{*}{ Component } & \multicolumn{6}{|c|}{ Saccade Size/Saccade Duration } \\
\hline & \multicolumn{2}{|c|}{$10 \mathrm{deg} / 52.22 \mathrm{msec}$} & \multicolumn{2}{|c|}{$20 \mathrm{deg} / 70.67 \mathrm{msec}$} & \multicolumn{2}{|c|}{$30 \mathrm{deg} / 84.17 \mathrm{msec}$} \\
\hline & Mean & SD & Mean & SD & Mean & SD \\
\hline \multicolumn{7}{|c|}{ Condition 1} \\
\hline $\begin{array}{l}\mathrm{N}_{1} \\
\mathrm{P}_{3}\end{array}$ & $\begin{array}{r}57.78 \\
141.55\end{array}$ & $\begin{array}{l}10.05 \\
23.30\end{array}$ & $\begin{array}{r}66.55 \\
157.89\end{array}$ & $\begin{array}{l}17.53 \\
23.86\end{array}$ & $\begin{array}{r}68.11 \\
164.33\end{array}$ & $\begin{array}{l}21.50 \\
21.59\end{array}$ \\
\hline \multicolumn{7}{|c|}{ Condition 2} \\
\hline $\begin{array}{l}\mathrm{N}_{1} \\
\mathrm{P}_{3}\end{array}$ & $\begin{array}{r}67.55 \\
163.77 \\
\end{array}$ & $\begin{array}{l}18.00 \\
18.41 \\
\end{array}$ & $\begin{array}{r}73.66 \\
176.44 \\
\end{array}$ & $\begin{array}{l}21.10 \\
19.18 \\
\end{array}$ & $\begin{array}{r}75.57 \\
189.22\end{array}$ & $\begin{array}{l}19.96 \\
19.31\end{array}$ \\
\hline
\end{tabular}

Notc $-N=9$. 


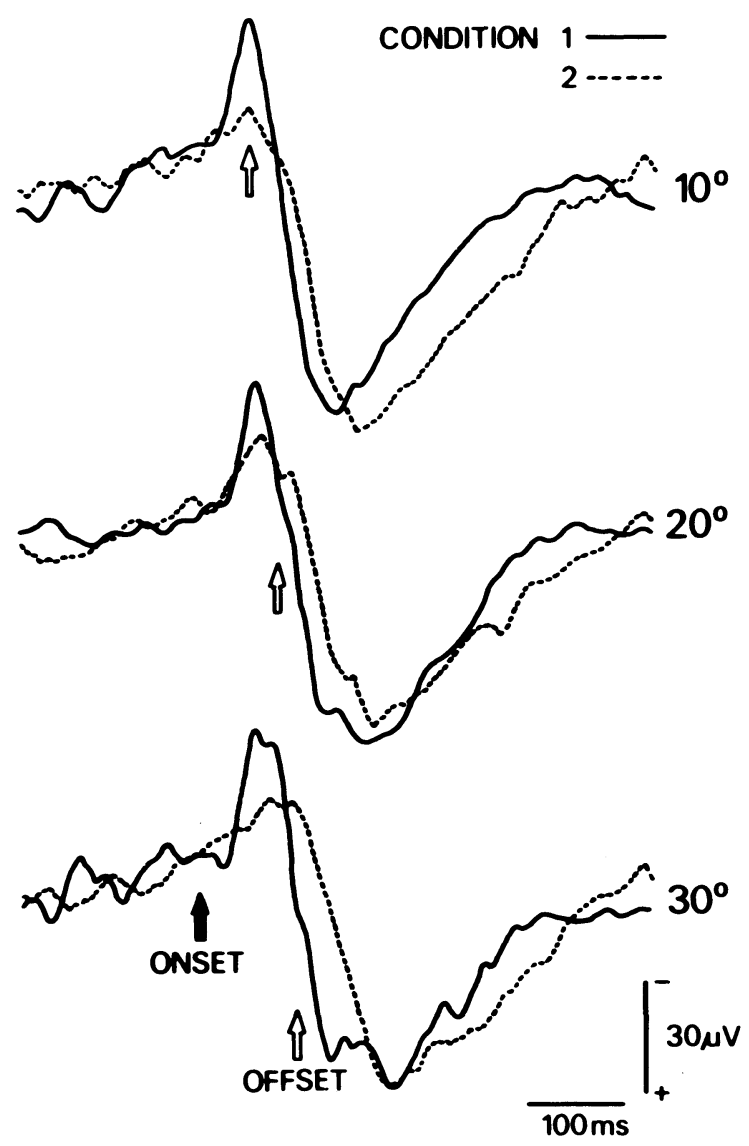

Figure 2. Grand average waveforms across all subjects according to saccade sizes. Solid line: Condition 1. Dotted line: Condition 2. Black arrow indicates saccade onset, white arrow, saccade offset.

cades of $10 \mathrm{deg}(\mathrm{p}<.05$, Wilcoxon test), the two remaining categories also show a similar tendency with difference values falling just short of significance.

The latency of the prominent positive component $\left(P_{3}\right)$ that appeared after saccade offset was also significantly shorter in the high- than in the low-luminance condition (overall means, 154.6 vs. $176.5 \mathrm{msec}$,

Table 2

Means and Standard Deviations for Amplitudes (in Microvolts) of the $N_{1}$ and $P_{3}$ Components in Conditions 1 and 2

\begin{tabular}{|c|c|c|c|c|c|c|}
\hline \multirow{3}{*}{$\begin{array}{l}\text { Com- } \\
\text { ponent }\end{array}$} & \multicolumn{6}{|c|}{ Saccade Size } \\
\hline & \multicolumn{2}{|c|}{$10 \mathrm{deg}$} & \multicolumn{2}{|c|}{$20 \mathrm{deg}$} & \multicolumn{2}{|c|}{$30 \mathrm{deg}$} \\
\hline & Mean & SD & Mean & SD & Mean & SD \\
\hline \multicolumn{7}{|c|}{ Condition 1} \\
\hline $\begin{array}{l}N_{1} \\
P_{3}\end{array}$ & $\begin{array}{l}45.88 \\
56.03\end{array}$ & $\begin{array}{l}20.09 \\
21.08\end{array}$ & $\begin{array}{l}49.51 \\
60.60\end{array}$ & $\begin{array}{l}23.87 \\
24.75\end{array}$ & $\begin{array}{l}56.37 \\
64.01\end{array}$ & $\begin{array}{l}23.94 \\
22.45\end{array}$ \\
\hline \multicolumn{7}{|c|}{ Condition 2} \\
\hline $\begin{array}{l}\mathrm{N}_{1} \\
\mathrm{P}_{3}\end{array}$ & $\begin{array}{l}23.97 \\
66.05\end{array}$ & $\begin{array}{l}10.07 \\
26.04\end{array}$ & $\begin{array}{l}35.24 \\
57.36 \\
\end{array}$ & $\begin{array}{l}15.68 \\
16.90\end{array}$ & $\begin{array}{l}32.28 \\
69.01\end{array}$ & $\begin{array}{l}23.74 \\
18.24\end{array}$ \\
\hline
\end{tabular}

Note $-N=9$. $\mathrm{p}<.01$, Wilcoxon test). The same tendency could be observed in all three size categories, the difference between Conditions 1 and 2 not reaching the .05 significance level only in the 30-deg category.

The amplitude of $P_{3}$ across all saccade sizes did not differ significantly between Conditions 1 and 2, the overall means being 60.2 vs. $64.1 \mu \mathrm{V}$. Separate comparisons among categories revealed, however, that in the case of 10-deg saccades the amplitude of $P_{3}$ was significantly greater in the low- than in the highluminance condition ( $p<.05$, Wilcoxon test).

\section{Lambda Potentials Accompanying Saccades in Darkness}

Saccades performed in total darkness (Condition 3) were also accompanied by waveforms resembling the lambda complex. As shown in Figure 1, the grand average waveform shows a broad negative component appearing between $50-90 \mathrm{msec}$ after saccade onset. The amplitude of this "endogenous" negativity was considerably smaller than that of the $\mathrm{N}_{1}$ component recorded in Conditions 1 and 2 (its mean value was around 10-15 $\mu \mathrm{V}$ ). It was followed by late components appearing a hundred or more milliseconds after saccade offset. The late components took the form of either a long-lasting positivity or a sequence of small positive/negative (alphalike) waves.

\section{The Effect of Saccade Size}

The peak latencies of the two prominent components $\left(\mathrm{N}_{1}\right.$ and $\left.\mathrm{P}_{3}\right)$ of the lambda potentials were measured in two ways: from saccade onset and from saccade offset. By this, we followed Yagi's (1979) approach, which was based on the following reasoning: saccade duration increases with saccade size; therefore, if a component is linked to the offset of the saccade, its latency, as measured from saccade onset, increases along with saccade size. When, however, its latency is measured from saccade offset, it does not change considerably with different saccade sizes. In contrast, components linked to saccade onset

Table 3

Means and Standard Deviations for $N_{1}$ and $P_{3}$ Latencies (in Milliseconds) From Saccade Offset in Conditions 1 and 2

\begin{tabular}{|c|c|c|c|c|c|c|}
\hline \multirow{3}{*}{$\begin{array}{l}\text { Com- } \\
\text { ponent }\end{array}$} & \multicolumn{6}{|c|}{ Saccade Size } \\
\hline & \multicolumn{2}{|c|}{$10 \mathrm{deg}$} & \multicolumn{2}{|c|}{$20 \mathrm{deg}$} & \multicolumn{2}{|c|}{$30 \mathrm{deg}$} \\
\hline & Mean & SD & Mean & SD & Mean & SD \\
\hline \multicolumn{7}{|c|}{ Condition 1} \\
\hline $\begin{array}{l}N_{1} \\
P_{3}\end{array}$ & $\begin{array}{r}6.89 \\
90.22\end{array}$ & $\begin{array}{l}14.26 \\
28.72\end{array}$ & $\begin{array}{l}-4.22 \\
88.67\end{array}$ & $\begin{array}{l}21.60 \\
30.04\end{array}$ & $\begin{array}{r}-17.78 \\
80.67\end{array}$ & $\begin{array}{l}28.12 \\
31.63\end{array}$ \\
\hline \multicolumn{7}{|c|}{ Condition 2} \\
\hline $\begin{array}{l}\mathrm{N}_{1} \\
\mathrm{P}_{3}\end{array}$ & $\begin{array}{r}13.88 \\
109.55 \\
\end{array}$ & $\begin{array}{l}18.02 \\
17.94 \\
\end{array}$ & $\begin{array}{r}-.67 \\
103.22 \\
\end{array}$ & $\begin{array}{l}27.26 \\
27.10 \\
\end{array}$ & $\begin{array}{r}-12.66 \\
102.99 \\
\end{array}$ & $\begin{array}{l}27.63 \\
25.21 \\
\end{array}$ \\
\hline
\end{tabular}

Note $-N=9$. 
show a different pattern, their latency measured from onset does not change much with saccades of different sizes.

Regression analysis was used to evaluate the relationship between latency/amplitude values and saccade size (Ostle, 1954). As shown in Table 1, the latency of $\mathrm{N}_{1}$ from saccade onset shows only a slight increase with increase of saccade size in both Condition 1 and Condition 2. In neither case was regression analysis significant $[F(1,25)=1.71$ and .73 , respectively].

Table 3 presents the mean latencies of the $N_{1}$ and $P_{3}$ components measured from saccade offset in Conditions 1 and 2. The peak latencies of $N_{1}$ from saccade offset can be fitted by a linear regression line, the slope of which is steeper and the direction of
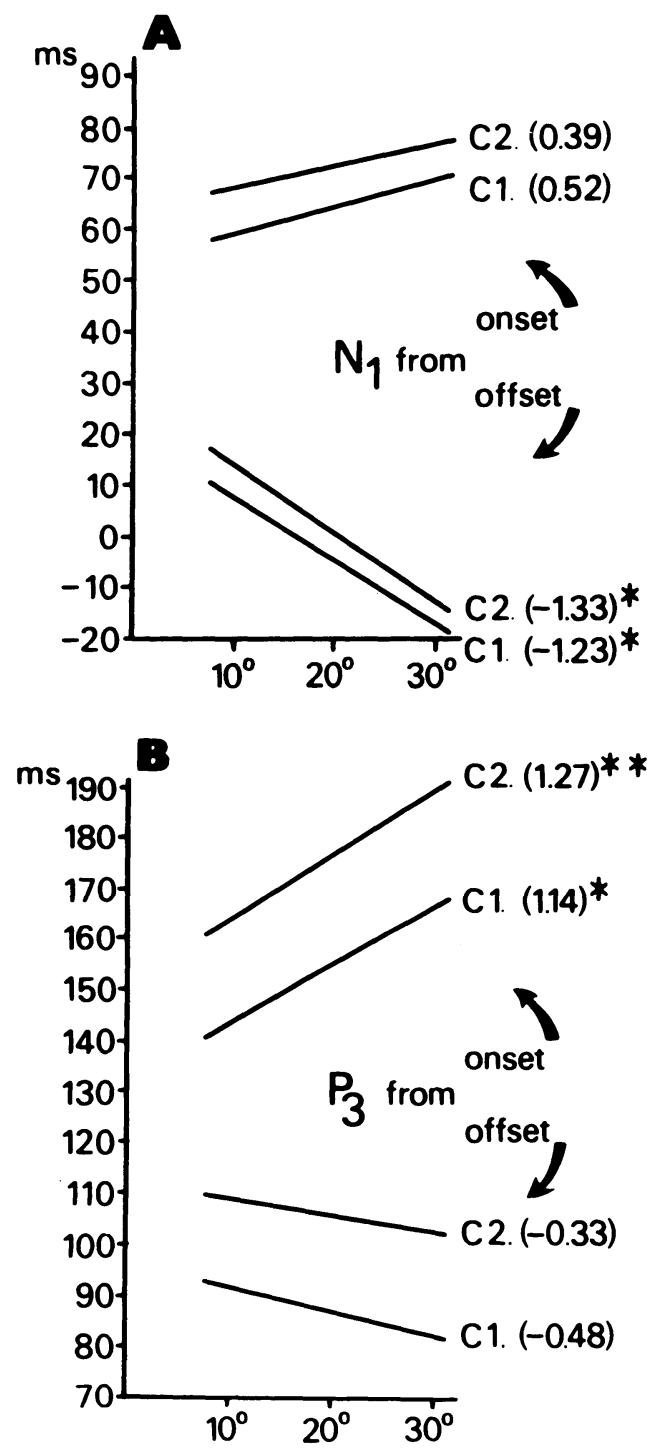

Figure 3. (A) Regression of $\mathrm{N}_{1}$ latency values on saccade sizes in Condition 1 (C1) and Condition 2 (C2). Numbers in parentheses indicate the slope of linear regression. (B) Regression of $P_{3}$ latency values on saccade sizes in Condition 1 (C1) and Condition 2 (C2). Numbers in parentheses indicate the slope of linear regression. ${ }^{\star} p<.05 .{ }^{\star \star} p<.01$. which is opposite to that of the regression line of $\mathrm{N}_{1}$ onset latencies (see Figure 3A). Regression analysis revealed significant linear relationships $[F(1,25)=$ 5.85 and 5.41, respectively, ps $<.05$ in both conditions] in both Condition 1 and Condition 2 . As the saccade duration increases, the $\mathrm{N}_{1}$ component peaks increasingly earlier in comparison with the offset of the saccade.

The latency from saccade onset of the $\mathrm{P}_{3}$ component shows a relatively steep increase with increasing saccade duration (Figure 3B). Regression analysys revealed significant linear relationships in both Condition 1 and Condition $2[\mathrm{~F}(1,25)=4.57(\mathrm{p}<.05)$ and $8.19(p<.01)$, respectively]. When, however, $P_{3}$ latency was measured from saccade offset, no significant relationship emerged in regression analysis for peak latencies with different saccade sizes $[F(1,25)$ $=.47$ and .36 , respectively].

Regression analysis did not reveal significant relationships between amplitude values of the prominent peaks in lambda potentials and saccade size, although in both conditions there was a tendency toward increasing amplitudes with increasing saccade sizes (see Table 2). In Condition 1, the linear regression coefficient was .52 for $\mathrm{N}_{1}$ and .40 for $\mathrm{P}_{3}$; in Condition 2, it was .72 for $N_{1}$ and .15 for $P_{3}$.

A small biphasic complex could often be observed between the prominent $N_{1}$ and $P_{3}$ peaks in the lambda potential ( $\mathbf{P}_{2}$ and $\mathbf{N}_{2}$ in Yagi's nomenclature), especially in Condition 1 . In Condition 1 , the mean peak latencies of $P_{2}$ were $83.3,94.3$, and $97.2 \mathrm{msec}$ in the three size categories; those of $\mathrm{N}_{2}$ were 104.5, 115.0 , and $119.4 \mathrm{msec}$. The linear regression coefficient was .68 for $P_{2}$ and 1.03 for $N_{2}(p<.10)$.

\section{DISCUSSION}

In the studies on lambda potentials in humans, there are controversies about the possible origin and functional role of the components of the potential appearing at the beginning of and during the saccades, respectively. The first prominent component in humans, a spike-like positivity $\left(P_{1}\right)$, peaks simultaneously with saccade onset. Becker, Hoehne, Iwase, and Kornhuber (1972) suggested that this component reflected volume-conducted activity of extra-ocular muscles. In a topographical study, Kurtzberg and Vaughan (1977) found such spike potentials to be maximal over frontal and parietal scalp areas. They suggested, therefore, that the spike-like potentials "represent a phasic discharge which is related to activation of the ocular musculature and is concurrently transmitted to other parts of the nervous system which are directly concerned with the programming of saccades" (Kurtzberg \& Vaughan, 1977, p. 327). Yagi also argued that, since the $P_{1}$ starts to develop $16 \mathrm{msec}$ earlier than the onset of eye movement, it might be of neural origin. In our study with 
monkeys, we did not find a comparable component in lambda potentials from the occipital lobe. This finding seems to support the notion that the $P_{1}$ component in humans originates from eye muscle activity reaching the scalp by volume conduction. However, the possibility that this component might be generated outside the striate cortex should be kept in mind, although a limited sampling of activity from the frontal and parietal cortices in three animals did not reveal any prominent spike-like positivity (Figure 4).

In psychophysical experiments, it has repeatedly been demonstrated (Woodworth, 1938; MacKay, 1970) that threshold elevation during saccades (suppression) is greater when the visual field is patterned. This observation has been substantiated by evoked potential measurements (Gross, Vaughan, \& Valenstein, 1967). Based on these facts, it seemed reasonable to hypothesize that the $\mathrm{N}_{1}$ component of the lambda potential which appears during the saccade might be related to retinal suppression, the strength of which in turn would depend on the luminance value of the patterned field. In an earlier study (Marton, Szirtes, \& Donauer, in press), we found, with six humans, that the $\mathrm{N}_{1}$ component of the lambda complex recorded from the scalp did not depend, in exactly the same way, on the level of luminance of the stimulus field as it did in the case of three monkeys with which the recordings were made from within the cortex. It therefore seemed necessary to analyze the dependence of the $\mathrm{N}_{1}$ component of cortical lambda potential on the luminance of the stimulus field using a larger animal sample.

A more thorough analysis of the relationship between the $\mathrm{N}_{1}$ component and stimulus luminance was also called for by Yagi's recent study (Yagi, 1979).
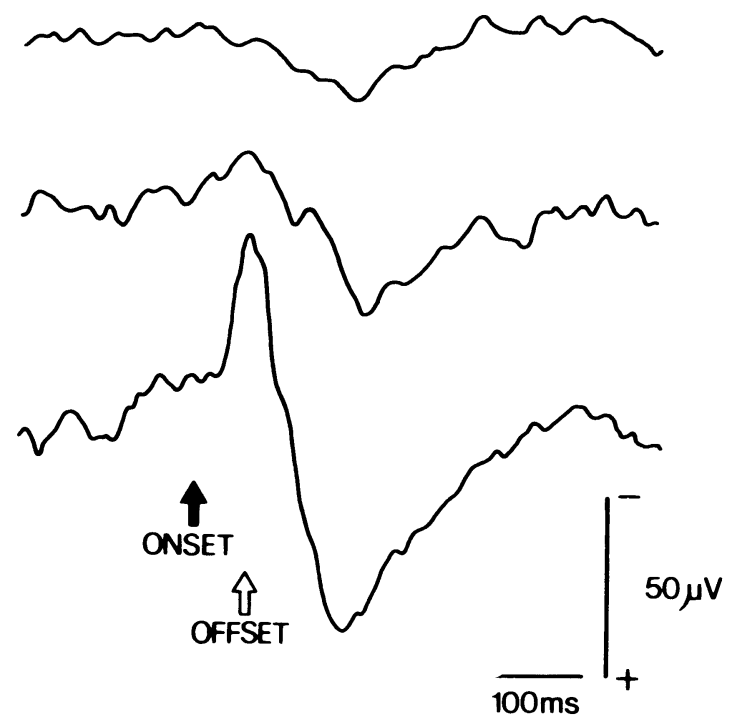

Figure 4. Grand average lambda potentials associated with 10-deg saccades in Condition 1 in three animals. From top to bottom: transcortical recordings from frontal, parietal, and occipital areas.
Based on his observations with humans, Yagi suggested that the $\mathrm{N}_{1}$ component might originate from eyemuscle activity, a conclusion that stands in sharp contrast with our earlier suggestion about the functional role of the $\mathrm{N}_{1}$ component of the lambda potential (Marton, Szirtes, \& Donauer, in press). While such a possibility is not ruled out entirely by our use of transcortical recordings, such a technique nevertheless seems to make Yagi's suggestion that the $\mathrm{N}_{1}$ could be a sign of volume-conducted eye-muscle activity improbable. Furthermore, the dependence of the $\mathrm{N}_{1}$ component on stimulus characteristics also suggests a neural origin: saccades over high-luminance gratings were associated in the monkey visual cortex with lambda potentials whose $\mathbf{N}_{1}$ component had a shorter peak latency and greater amplitude than those recorded during low-luminance conditions (see Figures 1 and 2). Therefore, these results lend support to our earlier suggestion that the $\mathrm{N}_{1}$ component might be closely related to retinal suppression which would be mobilized at different rates by visual fields of different luminance value. To collect direct evidence for this proposition, it will be necessary to record neuronal activity and lambda potentials simultaneously.

A further interpretation of the $\mathrm{N}_{1}$ component might be that it is an evoked potential component which reflects cortical activity generated by the onset of pattern movement across the retina. It has been reported that the onset of pattern movement can elicit lambdalike responses in cats (Ebersole \& Galambos, 1973) and in humans (Clarke, 1973a, 1973b) independently of pattern offset or reversal. This also supports the suggestions that the $\mathrm{N}_{1}$ component is related to image movement and associated inhibitory events (Kurtzberg \& Vaughan, 1977).

The fact that a broader endogenous negativity can be observed during saccades performed in darkness (see Figure 1) raises the possibility that extraretinal processes may also exert their influence in the same time range in which the $\mathrm{N}_{1}$ appears. Based on the results of single-unit recording and lesion experiments, other authors also have assumed simultaneous participation of retinal and extraretinal processes in suppression during saccades (Breitmeyer \& Ganz, 1976; Bridgeman, Hendry, \& Stark, 1975; Riggs, Merton, \& Morton, 1974; Torda, 1980; Volkmann, Schiek, \& Riggs, 1978). We suggest, therefore, that the $\mathrm{N}_{1}$ component accompanying saccades across a patterned field might be a combination of patternevoked and endogenous negativity, thus reflecing the interaction of retinal events and extraretinal processes.

This interpretation is also in harmony with the observed effect of saccade size on lambda components. Measuring the $\mathrm{N}_{1}$ latency from saccade onset, we found that its value increased only slightly with increasing saccade duration, and regression analysis showed this change to be nonsignificant. However, 
when $\mathrm{N}_{1}$ latencies were measured from saccade offset, the values increased inversely with saccade size and regression analysis revealed a significant linear change. Taken all together, these data suggest that the $\mathrm{N}_{1}$ component is related to processes linked to the beginning of the eye movement (such as suppression).

We found a significant linear relationship between saccade size and $P_{3}$ latency when measured from saccade onset both in Condition 1 and Condition 2, whereas $\mathbf{P}_{3}$ latencies were not influenced by saccade size when measured from saccade offset (see also the differences in the steepness of the regression lines in Figure 3). These relationships suggest a close link between $P_{3}$ and visual events associated with saccade offset. Therefore, the $\mathrm{P}_{3}$ component is viewed as a "fixational" component reflecting information pickup in the new fixation. A similar conclusion for humans was reached by Kurtzberg and Vaughan (1977) and by Yagi (1979). We also found in monkeys what had earlier been reported in human studies (Gaarder, Krauskopf, Graf, Kropfl, \& Armington, 1964; Lesèvre \& Rémond, 1973; Kurtzberg \& Vaughan, 1977; Marton et al., in press), namely, that the latency of this positive component lengthens as the luminance of the stimulus field is decreased. Lengthening of peak latency with decreased stimulus intensity is a common finding in human evoked potential studies (e.g., Regan, 1972) and thus supports the contention that $P_{3}$ is linked to the processing of stimuli in the new fixation.

We would like to point out the similarity (except for the $P_{1}$ and a late "saccadic" positivity) between the lambda complexes recorded from the scalp in man and the lambda potentials recorded transcortically from within the visual cortex in monkey. Beside the similarity in wave shape, the lambda complex in the monkey is somewhat less complex, which suggests the possibility that not all of the human lambda components originate in striate cortex. This is also indicated by the topographic data of Kurtzberg \& Vaughan (1977). Nevertheless, it is important to note that in both cases the main components of the lambda potential reacted similarly to change in luminance (Marton et al., in press). The different dependences of the $\mathrm{N}_{1}$ and $\mathrm{P}_{3}$ components on saccade size are also in accord with conclusions drawn from human studies, and suggest that further investigations of lambda potentials may help to understand the neural processes underlying a wide range of perceptual performances.

\section{REFERENCES}

Barlow, J. S., \& Ciganek, L. Lambda responses in relation to visual evoked response in man. Electroencephalography and Clinical Neurophysiology, 1969, 26, 183-192.

Becker, W., Hoenne, O., Iwase, K., \& Kornhuber, H. H. Bereitschaftspotential, prämotorische Positivierung und andere Hirnpotentiale bei sakkadischen Augenbewegungen. Vision Research, 1972, 12, 421-436.
Breitmeyer, B. G., \& Ganz, L. Implications of sustained and transient channels for theories of visual pattern masking, saccadic suppression, and information processing. Psychological Review, 1976, 83, 1-37.

Bridgeman, B., Hendry, D., \& Stark, L. Failure to detect displacement of the visual world during saccadic eye movements. Vision Research, 1975, 15, 719-722.

Clarke, P. G. H. Visual evoked potentials to changes in the motion of a patterned field. Experimental Brain Research, 1973, 18, 145-155. (a)

Clarke, P. G. H. Comparison of visual evoked potentials to stationary and to moving patterns. Experimental Brain Research, 1973, 18, 156-164. (b)

Cohen, B., \& Feldman, M. Potential changes associated with rapid eye movement in the calcarine cortex. Experimental Neurology, 1971, 31, 100-113.

Ebersole, J. S., \& Galambos, R. Lambda waves evoked by retinal stimulation in the absence of eye movements. Electroencephalography and Clinical Neurophysiology, 1973, 35, 39-47.

GaARDer, K., Krauskopf, J., Graf, V., Kropfl, W., \& Armington, J. C. Averaged brain activity following saccadic eye movement. Science, 1964, 146, 1481-1483.

Gross, E. G., Vaughan, H. G., Jr., \& Valenstein, E. Inhibition of visual evoked responses to patterned stimuli during voluntary eye movements. Electroencephalography and Clinical Neurophysiology, 1967, 22, 204-209.

Kurtzberg, D., \& Vaughan, H. G., Jr. Electrocortical potentials associated with eye movements. In V. Zikmund (Ed.), The oculomotor system and brain functions. London: Butterworths, 1973.

Kurtzberg, D., \& Vaughan, H. G., JR. Electrophysiological observations on the visuomotor system and visual neurosensorium. In J. E. Desmedt (Ed.), Visual evoked potentials in man: New developments. Oxford: Clarendon Press, 1977.

LESÈvRE, N., \& RÉmoND, A. Effects of contrasts on the visual evoked potentials related to eye movements. In V. Zikmund (Ed.), The oculomotor system and brain functions. London: Butterworths, 1973.

MacKAY, D. M. Elevation of visual threshold by displacement of retinal image. Nature, 1970, 225, 90-92.

MARTon, M., SzirTes, J., \& Donauer, N. A comparative study of averaged lambda potentials in man and monkey. In R. Sinz \& M. R. Rosenzweig (Eds.), Psychophysiology 1980. Jena: G. Fischer, in press.

Ostle, B. Statistics in research. Ames: Iowa State University Press, 1954.

REGAN, D. Evoked potentials in psychology, sensory physiology and clinical medicine. London: Chapman and Hall, 1972.

Rhodes, J. M., Lanoir, J., Saier, J., \& Naquet, R. Étude des réponses évoquées par les mouvements des yeux le long de la voie visuelle. Revue Neurologique, 1962, 107, 177-187.

Riggs, L. A., Merton, P., \& Morton, M. Suppression of visual phosphenes during voluntary saccadic eye movements. Vision Research, 1974, 14, 997-1011.

ScotT, D. F., \& Bickford, R. G. Stimulus indicators of summated human lambda responses. Archives of Neurology, 1969, 21, $277-284$.

ScotT, D. F., Lichtenfeld, F. R., \& BickFord, R. G. Lambdawave studies on the EEG of animals. Archives of Neurology, 1968, 18, 574-582.

TordA, C. Memory and dreams. Chicago: Walters, 1980.

Volkman, F. C., Schiek, A. M. L., \& RigGs, L. A. Time course of visual inhibition during voluntary saccades. Journal of the Optical Society of America, 1968, 58, 562-569.

Woodworth, R. S. Experimental psychology. New York: Holt, 1938.

YAGI, A. Saccade size and lambda complex in man. Physiological Psychology, 1979, 7, 370-376.

(Manuscript received October 5, 1981; revision accepted for publication March 10, 1982.) 